\title{
The Effects of a Nursing Simulation Education about Child Care with Acute Asthma Attacks on the Problem-Solving Process, Self-efficacy, and Learning Satisfaction for Nursing Students
}

\author{
Nayoung Choi $^{1}$ \\ ${ }^{1}$ Associate Professor, Department of Nursing Science, Andong National University, Republic of \\ Korea, choice4na@hanmail.net
}

\begin{abstract}
This study aimed to investigate the effects of nursing simulation education about child care with acute asthma attacks for nursing students. Nursing students that participated in this study were divided into experimental and control groups. The subjects in the control group received the video education and the subjects in the experimental group received the simulation education to observe the differences in the problem-solving processes, self-efficacy, and learning satisfaction. This study used a non-equivalent control pre-post design and data were analyzed using SPSS WIN 22.0. The general characteristics and the values of the variables along with percentages and standard deviation were analyzed. In addition, the subjects' homogeneity and t-test hypotheses were analyzed. The difference in the subjects' scores before and after the video education program were statistically significant in the self-efficacy $(t=3.08, p<.004)$ and learning satisfaction $(t=3.46, p<.003)$. The findings indicate that this simulation would be useful in improving self-efficacy and learning satisfaction for child care with an asthma attack in nursing students.
\end{abstract}

Keywords: Simulation, Problem, Self-efficacy, Satisfaction

\section{Introduction}

\subsection{Background}

Since students partake in clinical training in a real hospital environment, no form of mistakes is allowed[1]. Because the hospital environment is a vital area, patients could get a huge impact on the clinical training program of students.

In addition, for patients who have illnesses, guaranteeing their health and safety is first and foremost, thus, clinical training with children is regarded as the most difficult area for students during training.

The simulation-based learning is considered to get better students' self-efficacy and has been combined with the nursing clinical practice curricula[2] .

Due to the rise in qualitative care demands by hospital patients, students are not allowed to directly intervene and mostly participate in observation-focused clinical training[3][4]. Therefore, the opportunities for students to experience and acquire complex and various skills and experiences during clinical training are gradually being reduced, and the scope of clinical training is becoming more limited[5].

Therefore, students are expressing dissatisfaction with clinical training[3][4]. Thus, it can be

Received: July 06, 2020; 1st Review Result: August 26, 2020; 2nd Review Result: October 13, 2020 Accepted: November 30, 2020 
observed that further development and application of a complementary education program to clinical training is required as education progresses.

To address the limitations of clinical training, continuous research and application of simulation training based on clinical situations are being developed rapidly. Simulation-based education can improve the knowledge and skills of students by utilizing real, interactive professor-studying methods as opposed to traditional lecture-based education[6].

In addition, previous research showed that these aforementioned education methods are effective for improving clinical implementation skills[7]. Simulation-based education also allows the students to learn and practice practical clinical work in a hospital environment without infringing on the patients' rights[8]. In addition, the program allows students to acquire clinical safety, knowledge, and skills and raises the students' confidence[9] and satisfaction[10]. Therefore, simulation education can be more than just simulating the use of technical equipment but rather a means to maximize and replace reallife experience. Simulation education also provides its participants with real-life immersive situations and can be a guide on practical clinical affairs[11].

There are situations where the child patients, that students treat in clinical practice training at a general hospital, are more acute and bell proof than other patients. In addition, students without much experience may face large amounts of stress in a children's hospital where clinical treatment is executed promptly and in complex order. Therefore, there has been an increase in interest in simulation education and its applications in clinical training to overcome these difficulties and improve the patients' safety and clinical care.

Education programs that incorporate simulations as opposed to traditional methods of education eliminate the anxiety that students in clinical training may face in several situations and can be a safety education program to ensure that patients are not at risk. However, a suitable program must be tried and tested to ensure that students learn practical clinical affairs efficiently and reach certain learning goals in the required fields of nursing[12].

Unfortunately, there is a lack of research regarding nursing for children as opposed to other areas of nursing within South Korean academia. Therefore, in this study, scenarios of the most common occurring pediatric disease, acute asthma, were reproduced to test the effects of its problem solving process, self-efficacy, and learning satisfaction on nursing students via a simulation education program. The basic data and empirical results of the simulation-based education program for clinical training are also provided in this study.

\subsection{Purpose of Study}

The purpose of this study is to develop a nursing simulation-based education program for clinical situations of children with acute asthma attacks and to identify the effects of problem-solving processes, self-efficacy, and learning satisfaction after applying a video education simulation clinical practice and other simulation-based training for nursing students.

\subsection{Hypothesis}

\section{1) Hypothesis 1}

There is a significant difference in problem-solving processes scores between the experimental group who received simulation-based education on children patients with acute asthma attacks and the control group who received just video education.

\section{2) Hypothesis 2}

There is a significant difference in self-efficacy scores between the experimental group who 
received simulation-based education on children patients with acute asthma attacks and the control group who received just video education.

\section{3) Hypothesis 3}

There is a significant difference in learning satisfaction scores between the experimental group who received simulation-based education on children patients with acute asthma attacks and the control group who received just video education.

\section{Research Method}

\subsection{Research Design}

This study develops a nursing simulation scenario for educational purposes based on children patients with acute asthma attacks. The control group only received video education while the experimental group underwent the simulation education program. A nonequivalent control group pretest-posttest design ([Table 1]) is used to quantify the score differences via a questionnaire survey in the control group and experimental group to test the efficiency of the simulation program.

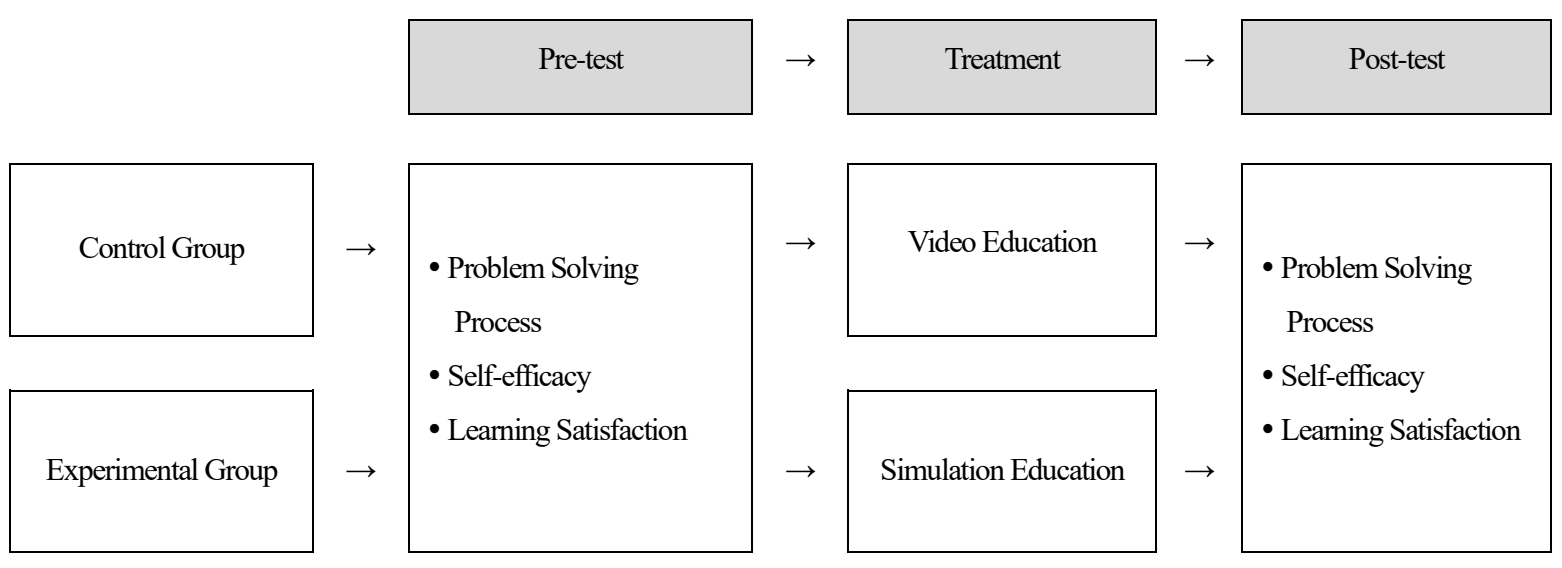

[Fig. 1] The Flow of Research

[Table 1] The Research Design

\begin{tabular}{|c|c|c|c|}
\hline & Pre-test & Treatment & Post-test1 \\
\hline Control group & $\mathrm{O}_{1}$ & $\mathrm{X}_{1}$ & $\mathrm{O}_{2}$ \\
\hline Experimental group & $\mathrm{O}_{1}$ & $\mathrm{X}_{2}$ & $\mathrm{O}_{2}$ \\
\hline
\end{tabular}

$\mathrm{O}_{1}, \mathrm{O}_{2}=$ Problem Solving Process, Self-efficacy and Learning Satisfaction

$\mathrm{X}_{1}=$ Video Education

$\mathrm{X}_{2}=$ Simulation-based Education 


\subsection{Sampling of Research Subject}

This study was conducted on university students randomly assigned experimental group and control group in their $3^{\text {rd }}$ year after carefully explaining the purpose, contents, and schedule of the research to students in groups and got signed papers from the subjects, who

1) were from 20 to 29 years old,

2) have not received a simulation education program,

3) were not suffering from any illness or mental disorder,

4) can communicate, understand the research, and voluntarily agreed to it

To calculate the sample size of the study, the $\mathrm{G}^{*}$ power sample size computation program[13] was used along with ANOVA repeated measure, interaction variables, and the parameters of the effect size at 0.25 , statistical significance at 0.05 , statistical power at $80 \%$, and correlation coefficient at 3 . The sample size computation yielded that a sample size of 23 for both the experimental group and the control group was required. Therefore, total of 46 subjects from a university were randomly assigned to two groups and groups of 3 were formed.

\subsection{Research Tool}

\subsubsection{Problem Solving Process}

To measure the problem-solving processes of the subjects, the metric developed by Woo (2000)[14] was modified and complemented after analysis. In addition, 3 nursing professors computed the validity coefficient to examine the content validity of the study. Only questions that had a Content Validity Index (CVI) score of at least 0.80 made it to the final questionnaire. This field of the questionnaire was composed of 25 questions and answers ranged from 1 indicating 'Not at all', to 5 indicating 'Very likely'. This answer scale was measured by the Likert criterion which calculates that a higher score indicates a higher problem-solving process in the subject. The problem-solving processes field had a degree of reliability of Cronbach's $\alpha$ value of 0.88 .

\subsubsection{Self-efficacy}

The self-efficacy criterion was modified from Hong's scale (1995)[15] after examination and content validity verification from 3 nursing professors. After the content validity checks, a total of 23 questions were left for this field in the survey questionnaire. Each question's answer scale was based on the Likert scale from 1 to 5 with a higher score indicating higher self-efficacy. This field had a degree of reliability of Cronbach's $\alpha$ value of 0.90 .

\subsubsection{Learning Satisfaction}

To compute learning satisfaction in the survey, questions used in Kim's study (2015)[16] were used after modification and complementation. The content validity was verified by 3 different nursing professors and the answers were based on a Likert scale of 1 to 10 , with a higher score indicating a higher learning satisfaction. This field had a degree of reliability of Cronbach's $\alpha=.89$

\subsection{Research Procedure}

\subsubsection{Simulation Scenario Development Stages}

This study developed simulation scenarios on different nursing processes in children patients based on examples in pediatric nursing textbook materials after careful validation and examination by 2 child nursing professors and 1 pediatrician. After receiving opinions on and fixing errors in the simulation 
program, the program was initially tested on 3 students and modified such that the program could be conducted within a 15-minute frame.

The scenario is mainly constructed of a 6-month-old child patient who is diagnosed with acute asthma attacks a day prior and has difficulty breathing. The students are then required to undergo the nursing process from inspection, diagnosis, arbitration, and evaluation. Then the students are tasked with choosing the correct nursing skills out of the core nursing techniques required to nurse child patients with acute asthma attacks. The subjects are then asked to perform the proper nursing skill in front of the other 2 subjects in the group and select the skill which appears to be the most satisfactory.

\subsubsection{Data Collection Stage}

After receiving approval and signed waivers of intent from the $3^{\text {rd }}$ year nursing students', the survey data on the nursing students' performance was collected from October 28th, 2019 to November $22^{\text {nd }}$ of the same year. After a brief orientation that explained the process to the experimental and control group, the subjects answered the survey questionnaire that included questions on problem-solving processes, self-efficacy, and learning satisfaction to measure the subjects' capabilities before the program. The control group only received video education on nursing child patients with acute asthma attacks and the experimental group received both the video education and the simulation program. The survey questionnaire was answered by both groups following both education programs again.

[Table 2] Simulation Scenario for Care of Child with Acute Asthma Attack

\begin{tabular}{|c|c|c|c|c|}
\hline No & Stage & $\begin{array}{c}\text { Time } \\
\text { (minute) }\end{array}$ & Mannequin State (lab data etc.) & Nursing Intervention \\
\hline 1 & $\begin{array}{c}\text { Assessment } \\
\text { Stage }\end{array}$ & $\begin{array}{c}0-5 \\
\text { minute }\end{array}$ & $\begin{array}{l}\text { - } \mathrm{T}: 37.8^{\circ} \mathrm{C} \\
\text { - } \mathrm{P}: 133 \text { times/min } \\
\text { - } \mathrm{R}: 46 \text { times/min } \\
\text { - } \mathrm{SpO}_{2}: 86 \%\end{array}$ & $\begin{array}{l}\text { - Washing hand } \\
\text { - Check ID band } \\
\text { - Check vital sign } \\
\text { - Check safety \& general appearance } \\
\text { - Check cyanosis \& } \mathrm{SpO}_{2} \\
\text { - Report to Dr \& get Doctor's Order }\end{array}$ \\
\hline 2 & Crisis Stage & $\begin{array}{c}5-9 \\
\text { minute }\end{array}$ & $\begin{array}{l}\text { - Doctor's Order: } \\
\text { - V/S } \\
\text { - Chest physiotherapy } \\
\text { - } \mathrm{ECG}, \mathrm{SpO}_{2} \text { monitoring } \\
\text { - } \mathrm{O}_{2} 2 \mathrm{~L} / \mathrm{min} \text { via nasal cannula } \\
\text { - Ventolin nebule } 2.5 \mathrm{mg} \\
\text { (Salbutamol) } 1 \mathrm{amp} \text { inhalation } \\
\text { 1/d via nebulizer } \\
\text { - Prednisolone } 1-2 \mathrm{mg} / \mathrm{d} \text { p.o. } \\
\text { - prn. suction }\end{array}$ & $\begin{array}{l}\text { - Preparing } \mathrm{O}_{2} \text { and applying a nasal cannula } \\
\text { - Provides information and emotional support to } \\
\text { the } \\
\text { child patient's mother } \\
\text { - Applies chest physiotherapy and teaches the } \\
\text { parent } \\
\text { how to } \\
\text { - Administers medicine and nebulizer } \\
\text { - Provides detailed information about the } \\
\text { application } \\
\text { of the nebulizer }\end{array}$ \\
\hline
\end{tabular}


The Effects of a Nursing Simulation Education about Child Care with Acute Asthma Attacks on the Problem Solving Process, Self-efficacy and Learning Satisfaction for Nursing Students

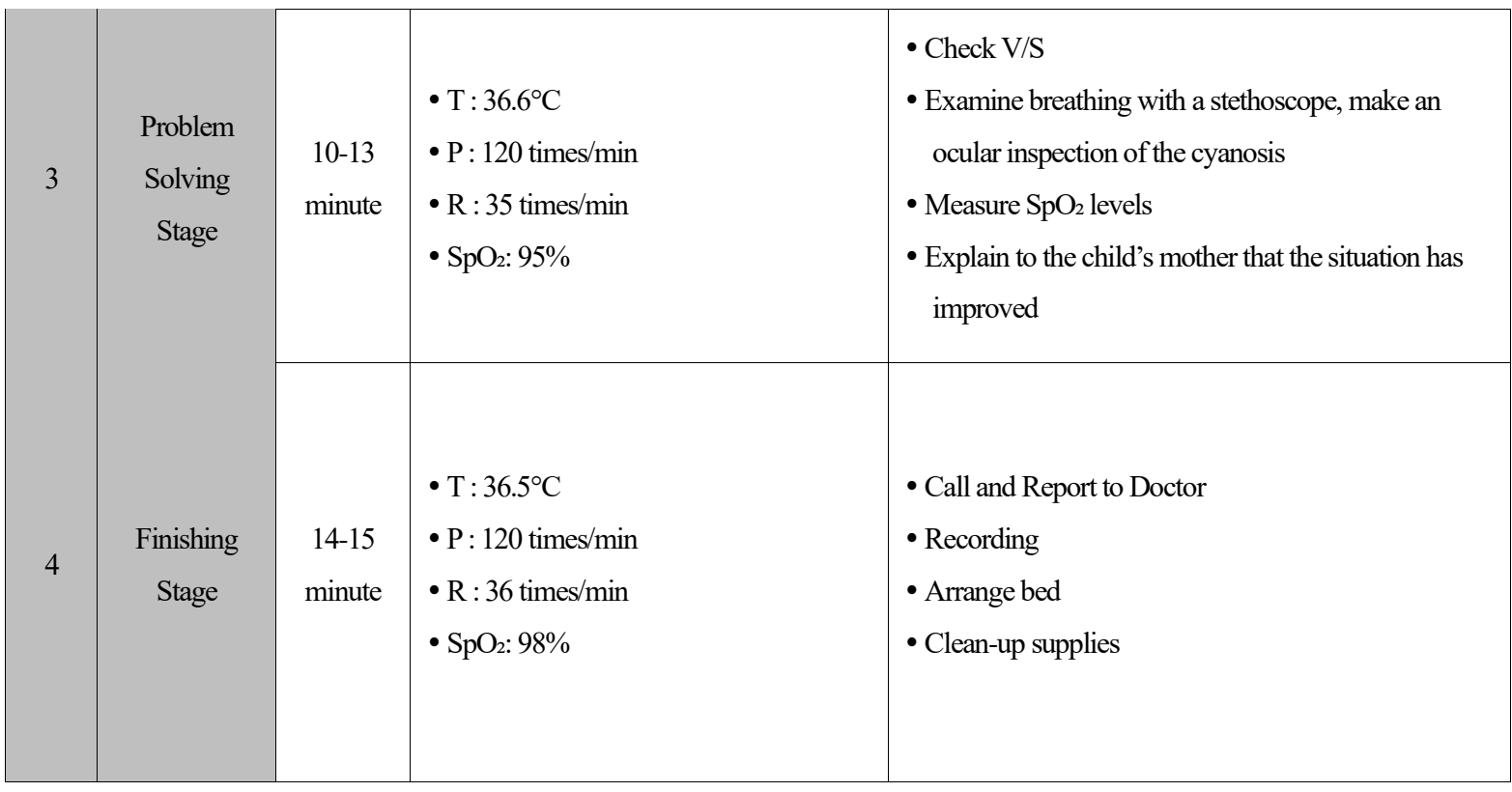

\subsection{Analysis of Data}

The data collected in this study were analyzed using the SPSS WIN 22.0 statistical program. The subject data's general characteristics and variables' frequency, percentages, means, and standard deviation were all collected. The subjects' general characteristics and the two groups problem-solving processes, self-efficacy, and learning satisfaction before and after the program were analyzed for homogeneity and t-test hypotheses. The degree of reliability was verified by Cronbach's $\alpha$ value.

\section{Results}

\subsection{General Characteristics of Subjects}

The general characteristics of the subjects of the simulation-based nursing education program on child patients with acute asthma attacks were verified. The variables included age, religion, and academic performance before the program, and it was observed that for both the experimental and control group, there was no statistically significant difference $(p>.05)$ between the two groups.

[Table 3] The General Characteristics of Subjects $(\mathrm{N}=46)$

\begin{tabular}{|c|c|c|c|c|}
\hline \multirow{2}{*}{ Characteristics } & Categories & $\begin{array}{c}\text { Total(N=46) } \\
\mathrm{n}(\%)\end{array}$ & $\begin{array}{c}\text { Control group( } \mathrm{n}=23) \\
\mathrm{n}(\%)\end{array}$ & $\begin{array}{c}\text { Experiment group( } \mathrm{n}=23) \\
\mathrm{n}(\%)\end{array}$ \\
\hline \multirow{2}{*}{ Age(year) } & $19 \sim 21$ & $15(32.6)$ & $7(30.4)$ & $8(34.8)$ \\
\cline { 2 - 5 } & $22 \sim 24$ & $26(56.5)$ & $13(56.5)$ & $13(56.5)$ \\
\cline { 2 - 5 } & $\geq 25$ & $5(10.9)$ & $3(13.1)$ & $2(8.7)$ \\
\hline
\end{tabular}




\begin{tabular}{|c|c|c|c|c|}
\hline \multirow{3}{*}{ Religion } & Yes & $27(58.7)$ & $13(56.5)$ & $14(60.9)$ \\
\cline { 2 - 5 } & No & $19(41.3)$ & $10(43.5)$ & $9(39.1)$ \\
\hline \multirow{2}{*}{$\begin{array}{c}\text { Academic records } \\
\text { Before semester }\end{array}$} & $2.0 \sim 2.9$ & $2(4.4)$ & $1(4.4)$ & $1(4.4)$ \\
\cline { 2 - 5 } & $3.0-3.9$ & $29(63.0)$ & $14(60.8)$ & $15(65.2)$ \\
\hline
\end{tabular}

\subsection{Test of Hypothesis}

\subsubsection{Hypothesis 1}

To test Hypothesis 1 that "There is a significant difference in problem-solving processes scores between the experimental group who received simulation-based education on children patients with acute asthma attacks and the control group who received just video education.", the problem-solving processes score of both the experimental and control group were verified before and after the program. The control group had an average score of problem-solving processes of 87.62 before the program and 97.04 after for an average increase of 9.42. However, the experimental group had an average problemsolving processes score of 87.91 before and 97.72 after the simulation program with an increase of 9.81. Therefore, it was observed that there wasn't a statistically significant difference $(\mathrm{t}=0.05, \mathrm{p}$ $<.961)$ and Hypothesis 1 was dismissed ([Table 3]).

\subsubsection{Hypothesis 2}

To test Hypothesis 2 that "There is a significant difference in self-efficacy scores between the experimental group who received simulation-based education on children patients with acute asthma attacks and the control group who received just video education.", the self-efficacy scores of the experimental and control group were compared before and after the program. The control group had an average self-efficacy score of 71.26 before the video education program and an average score of 74.09 after an increase of 2.83. On the other hand, the experimental group had an average self-efficacy score of 72.18 before the simulation-based training and an average score of 78.59 for an increase of 6.41. Therefore, it was observed that there was a statistically significant difference in self-efficacy scores $(\mathrm{t}=3.08, \mathrm{p}<.004)$ between the two groups, and Hypothesis 2 was supported ([Table 3$])$.

\subsubsection{Hypothesis 3}

To test Hypothesis 3 that "There is a significant difference in learning satisfaction scores between the experimental group who received simulation-based education on children patients with acute asthma attacks and the control group who received just video education.”, the learning satisfaction between the two groups were compared before and after the program. The average learning satisfaction score of the control group was 22.71 before the video education program and 25.42 after the program for an increase of 2.71. For the experimental group, the average learning satisfaction score was 23.30 before the simulation-based training and 29.87 after for an increase of 6.17 . Therefore, it was observed that there was a statistically significant difference in score increases between the two groups $(\mathrm{t}=3.46, \mathrm{p}<.003)$, and Hypothesis 3 was supported ([Table 4$]$ ). 
[Table 4] The Comparison of Variables $(\mathrm{N}=46)$

\begin{tabular}{|c|c|c|c|c|c|c|c|c|}
\hline \multirow{2}{*}{ Variables } & \multicolumn{3}{|c|}{$\begin{array}{l}\text { Control group } \\
\text { M(SD) }\end{array}$} & \multicolumn{3}{|c|}{$\begin{array}{l}\text { Experimental group } \\
\qquad \mathrm{M}(\mathrm{SD})\end{array}$} & \multirow{2}{*}{$\mathrm{t}$} & \multirow{2}{*}{$p$} \\
\hline & Pre-test & Post-test & $\Delta \mathrm{M}$ & Pre-test & Post-test & $\Delta \mathrm{M}$ & & \\
\hline $\begin{array}{l}\text { Problem Solving } \\
\text { Process }\end{array}$ & $\begin{array}{c}87.62 \\
(16.31)\end{array}$ & $\begin{array}{c}97.04 \\
(13.37)\end{array}$ & $\begin{array}{c}9.42 \\
(15.84)\end{array}$ & $\begin{array}{c}87.91 \\
(17.39)\end{array}$ & $\begin{array}{c}97.72 \\
(15.43)\end{array}$ & $\begin{array}{c}9.81 \\
(16.01)\end{array}$ & 0.05 & .961 \\
\hline Self-efficacy & $\begin{array}{l}71.26 \\
(4.68)\end{array}$ & $\begin{array}{l}74.09 \\
(3.79)\end{array}$ & $\begin{array}{c}2.83 \\
(3.91)\end{array}$ & $\begin{array}{l}72.18 \\
(3.93)\end{array}$ & $\begin{array}{l}78.59 \\
(2.85)\end{array}$ & $\begin{array}{c}6.41 \\
(3.67)\end{array}$ & 3.08 & $.004 *$ \\
\hline $\begin{array}{l}\text { Learning } \\
\text { Satisfaction }\end{array}$ & $\begin{array}{l}22.71 \\
(4.05)\end{array}$ & $\begin{array}{l}25.42 \\
(3.81)\end{array}$ & $\begin{array}{c}2.71 \\
(3.92)\end{array}$ & $\begin{array}{l}23.30 \\
(3.82)\end{array}$ & $\begin{array}{l}29.87 \\
(3.79)\end{array}$ & $\begin{array}{c}6.17 \\
(3.80)\end{array}$ & 3.46 & $.003 *$ \\
\hline
\end{tabular}

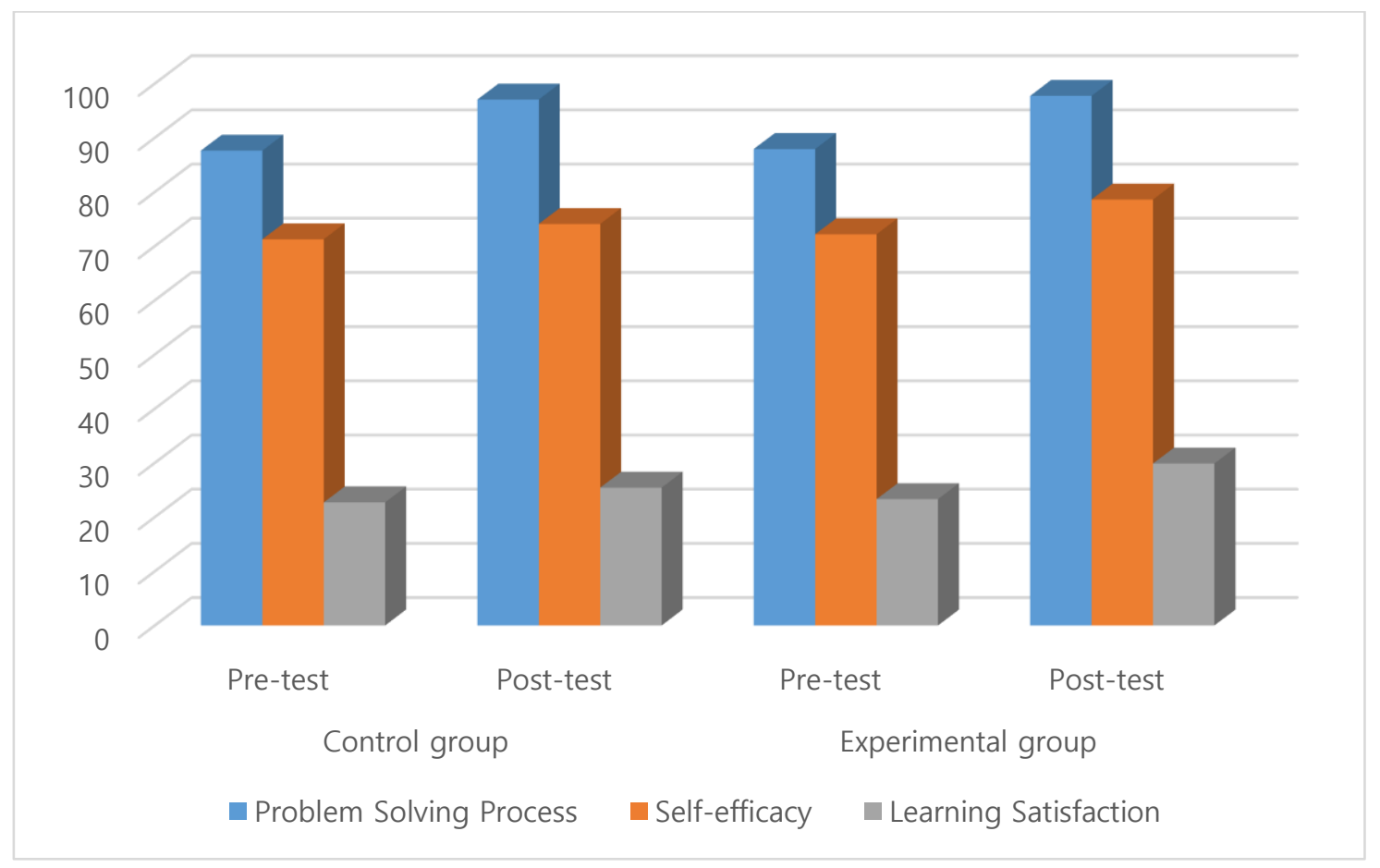

[Fig. 2] The Comparison of Variables

\section{Discussion}

This study developed and applied a simulation-based child nursing training program based on a scenario dealing with a child patient with acute asthma attacks. This study attempted to compare and contrast the problem-solving processes, self-efficacy, and learning satisfaction of nursing students before and after the simulation-based training to develop a solid foundation for the nursing education program.

The application of this study's simulation-based training about child care with asthma attack showed statistically significant increases in the self-efficacy and learning satisfaction scores of the 
nursing students. There were the results of Mieure et. al. (2010)[17] showed that simulation-based training on cardiopulmonary resuscitation increased significantly self-efficacy. But the result of this simulation-based training about child care with athma attack could be very rare. The simulation-based training was inferred to have brought higher interest to the material because the students were able to actively experience the nursing situation at hand. This resulted in higher self-efficacy and learning satisfaction in the students. Therefore results of this study could be applied to the simulation training programs for nursing students at the hospital.

Problem-solving processes emphase on the individual's thought-process to lead to problem-solving and decision-making and refer to the individual's disposition and habits that use these abilities[18]. Jin-Ju Yang's study (2008)[12] showed that students subject to a 6 week-long education program based on simulation were able to increase their problem-solving processes. However, in this study, there was not a statistically significant difference in problem-solving processes between the control group that received only video education and the experimental group that underwent the simulationbased training $(\mathrm{t}=0.05, \mathrm{p}<.961)$.

Therefore, it can be inferred that decision-making abilities and the ability to use individual habits may require a more concentrated, extended education program. Increasing one's problem-solving processes in such a short period may be difficult and more research is required to understand a more focused, extended period education program for problem-solving processes.

There was a limitation that the results of this study could not be generalized. Because this research was conducted with one nursing program at a school, and convenience samples were used.

However, there is significance in the fact that the simulation-based nursing training on child patients with acute asthma attacks was able to increase the students' self-efficacy and learning satisfaction.

\section{Conclusion}

The findings of this study indicated that nursing simulation education would be useful in improving self-efficacy and learning satisfaction for child care with asthma attacks in nursing students.

Nevertheless, further research on extended simulation-based nursing training programs on various subjects and a wide range of illnesses is required to fully understand the positive and negative effects of these nursing simulation-based education programs.

\section{References}

[1] M. R. Eom, H. S. Kim, E. K. Kim, K. Y. Seong, Effects of Teaching Method using Standardized Patients on Nursing Competence in Subcutaneous Injection, Self-Directed Learning Readiness and Problem Solving Ability, Journal of Korean Academy of Nursing, (2010), Vol.40, No.2, pp.151-160, DOI: 10.4040/jkan.2010.40.2.151

[2] B. O. Lee, H. F. Liang, T, P. Chu, C. C.Hung, Effects of simulation-based learning on nursing student competences and clinical performance, Nurse Education in Practice, (2019), Vol.41, pp.1-7, DOI: 10.1016/j.nepr.2019.102646

[3] M. Y. Park, S. Y. Kim, A Qualitative Study of Nursing Students' First Clinical Experience, The Journal of Korean Academic Society of Nursing Education, (2000), Vol.6, No.1, pp. 23-35.

[4] J. J. Yang, A Study of the Influencing Factors on Assertiveness, Clinical Stress and Nursing Performance in Nursing Students, The Journal of Kwangju Health College, (2000), Vol.25, pp.393-417.

[5] L. L. McCausland, C. C. Curran, P. Cataldi, Use of a Human Simulator for Undergraduate Nurse Education, International Journal of Nursing Education Scholarship, (2004), Vol.1 No.1, pp.1-17, DOI: 10.2202/1548-923X.1035

[6] W. M. Nehring, F. R. Lashley, Current Use and Opinions Regarding Human Patients Simulators in Nursing Education: An International Survey, Nursing Education Perspectives, (2004), Vol.25, No.5. pp.244-248. 
[7] L M. Haskvist, E. C. Koop, Students Struggling in Clinical? A new role for the patients simulator, The Journal of Nursing Education, (2004), Vol.43, No.4, pp.181-184, DOI: 10.3928/01484834-20040401-06

[8] A. Wilford, T. J. Doyle, Integrating Simulation Training into the Nursing Curriculum, British Journal of Nursing, (2006), Vol.15, No.17, pp.926-930, DOI: 10.12968/bjon.2006.15.17.21907

[9] P. Moule, A. Wilford, R. Sales, L. Locker, Student Experiences and Mentor Views of the Use of Simulation for Learning, Nurse Education Today, (2008), Vol.28, No.7, pp.790-797, DOI: 10.1016/j.nedt.2008.03.007

[10] M. N. Bremmer, K. Aduddell, D. N. Bennett, J. B. Vanceest, The use of human patient simulators: best practices with novice nursing students, Nurse Educator, (2006), Vol.31, No.4, pp.170-174, DOI: 10.1097/00006223200607000-00011

[11] D. M. Gaba, The Future Vision of Simulation in Health Care, Quality \& Safety in Health Care, (2004), Vol.13, pp.210, DOI: 10.1136/qhc.13.suppl_1.i2

[12] J. J. Yang, Development and Evaluation of a Simulation-based Education Course for Nursing Students, Korean Journal of Adult Nursing, (2008), Vol.20, No.4, pp.548-560.

[13] E. Erdfelder, F. Faul, A. Buchner, G POWER: A General Power Analysis Program, Behavior Research Methods, Instruments \& Computers, (1996), Vol.28, pp.1-11, DOI: https://doi.org/10.3758/BF03203630

[14] O. H. Woo, The Effects of a PBL on the Problem Solving Process of Students by their Meta-cognitive Levels, Korea National University of Education, Master Thesis, (2000)

[15] H. Y. Hong, The Relations of Perfectionism, Self-efficacy and Depression, Ewha Womans University, Master Thesis, (1995)

[16] E. J. Kim, The Effect of Flipped Learning Strategy on Motivation, Academic Achievement, and Self-directed Learning of Junior College Students, Incheon University, Master Thesis, (2015)

[17] K. D. Mieure, W. R. Vincent, M. R. Cox, M. D. Jones, A High-fidelity Simulation Mannequin to Introduce Pharmacy Students to Advanced Cardiovascular Life Support, American Journal of pharmaceutical Education, (2010), Vol.74, No.2, p.22, DOI: https://doi.org/10.5688/aj740222

[18] N. C. Facion, P. A. Facion, C. A. Sanchez, Critical Thinking Disposition as a Measure of Competent Clinical Judgement: The Development of the California Critical Thinking Disposition Inventory, Journal Nursing Education, (1994), Vol.33, No.8, pp.345-350, DOI: 10.3928/0148-4834-19941001-05 